This book is a welcome addition to the literature on ethical issues as they affect children, and deserves to be widely used by teachers in child health care.

RICHARD WEST

Medical Postgraduate Department, University of Bristol

\section{Changing human reproduction: social science perspectives}

\author{
Edited by Meg Stacey, London, \\ Sage, 1992,186 pages, $£ 9.95$
}

This is a collection of essays by social scientists about some of the social and economic aspects of the current revolution in reproduction. It is edited by Meg Stacey, Emeritus Professor of Sociology at the University of Warwick. In her introduction she complains that the enlightenment that might have been offered to those involved in this field by social research and analysis has been neglected to the detriment of all concerned.

Naomi Pfeffer discusses the vexed question of resources and points to the large sums of money involved in providing even modest fertility services. Thus most IVF treatment takes place in the private sector. She discusses the implications of 'these quasi private clinics' for the new political economy of health care and concludes: 'Now more than ever before, money and social status are determining who can get treatment for infertility in Britain'. A similar situation prevailed with regard to abortion in the years before the 1967 Abortion Act was passed, and even now barely half the women who need abortions are able to obtain them within the NHS. Money has often been the key to unlocking medical treatment and this is unlikely to change fast in the present circumstances of the National Health Service. Sarah Franklin discusses the "changing landscape of conception' from a cultural and anthropological point of view. Frances Price concentrates on multiple births which often result from fertility treatment. Such infants are more likely than others to be born disabled and with low birthweights. Research has already shown that family and friends are only ready and willing to provide help for a short time after birth and that social and community help is meagre. How much sense does it make to spend large resources on producing vulnerable small babies, when few resources are made available for caring for them? This is a key social and ethical question, as well as an economic one. Erica Haimes raises complex questions about privacy and the right to know about one's genetic inheritance. Marilyn Strathern develops this theme with her observation: 'What might be good for the child is not necessarily good for the parents'. The concluding chapter reaffirms the view that birth is as much a social and culturally conditioned event as a biological one, and in view of this, all these new techniques and their consequences need careful social analysis.

It would be hard to disagree with this argument. Advances in the science and technology of reproduction will not, however, wait upon long-term social research. Since the publication of this book, further startling developments have taken place, most recently the births of babies to two elderly women. Two key issues arise which have ethical implications. Do these developments offer more choice to women? Clearly, they do. Will babies born by these means emerge at least as happy and healthy as children born by conventional means? In the nature of things, this cannot be determined for many years. Meanwhile, science marches on. This is a well-timed, thought-provoking book. Further economic and financial analysis would have been welcome. Do these new methods of reproduction result in the births of a higher proportion of handicapped babies who are expensive to care for, as some have suggested? If so, is it ethical to consider providing such facilities without full screening and abortion facilities being made available as part of the service? A parallel collection of essays focusing on the ethical implications of the new childbirth would be welcome to complement this volume.

MADELEINE SIMMS Lately Senior Research Officer, Institute for Social Studies in Medical Care, London

\section{The ethics and politics of human experimentation}

Paul M McNeill, Cambridge,

Cambridge University Press, 1993, 315 pages, $£ 35.00 \mathrm{hb}$
For those interested or involved in the evolution of the process of ethical review of research on humans, this book would make a useful starting point. The author's recommendation for improving the balance of opinions available on such committees emerges during the course of it. Initially, evidence is adduced that research ethics committees (or institutional review boards in the United States) were developed following the realisation that unethical experiments on humans were continuing in spite of the historical abhorrence of revelations of German atrocities committed in the name of science during World War II. Other historical and indeed recent examples of unethical unreviewed research are cited. Research ethics committees have the task of applying ethical principles and rules of ethics to research proposals with a view to protecting the interests of the research subjects. The author develops his arguments for the need, where it has not occurred, to establish a set of principles to which such committees would adhere and he asserts the need to establish this within the law of the country to ensure that ethics committees are not able to exert too wide a discretion in their decision-making, although a certain degree of discretion is necessary.

A major thesis of the book revolves around the question of balanced representation on the committees themselves. Until now, many committees have been based at, or in relation to, an institution that has a research function so that members of the committee from the staff of the institution may have difficulty in acting in an unbiased way. They will, of necessity, have commitments to the success of research within the institution and they themselves may derive benefit from research publications. This is increasingly the situation, for example, in the UK, where government researchfunding is becoming more focused in its distribution, based on grading of an institution's research contribution. The conflict of interests in making decisions on the ethical issues pertaining to research projects could therefore impair the ability of such committee members to reach an unbiased balanced decision in regard to protecting the interests of the research subjects. It is asserted that because the balance of power and influence on ethics committees is weighted in favour of the institution's protagonists, partly because of their knowledge and expertise and partly from their position or status, those members from lay 
backgrounds who are effectively present representing their individual views rather than those of any community group, may be unclear as to their role and feel inhibited in expressing their views. Unless given training and guidance of what is expected of them they are likely to be able to contribute little.

In reviewing the methods of working of the committees in several countries, the author has found that the general lack of impact made by most lay representatives results, in practice, in the ethics review becoming a process of self-regulation by researchers and research institutions. Although the author provides some suggestions as to how the furtherance of the interests of subjects of research might be achieved on such committees, ie, by projecting the role of society both in the promotion of research and in the protection of research subjects, this can be difficult. He advocates the appointment of equal numbers of research and subject representatives and suggests that subject representatives should have support from groups they represent, such as the Community Health Councils in the UK. Indeed he feels that such members should be accountable to the human participants in research and receive support from groups representing these individuals. Another way of reducing the imbalance that arises from the influence of the research representatives would be to split the function of the committee, having a separate scientifically-based committee deciding on the scientific validity of a proposal before the submission reaches the ethics committee. This would lead to more equality of influence in the final decisionmaking on the ethical issues. The book provides useful appendices and references although there is a tendency to unnecessary repetition between chapters.

If support is to be given to the arguments put forward, the cost in terms of education and even in the recognition of the work of lay subject representatives - particularly if any surveillance of ongoing projects is to be taken on, as advocated - will have to be met. This, however, does not appear unreasonable in a world that is becoming less altruistic yet more vocal in its concerns to protect research subjects from unethical research.

R P A RIVERS Department of Paediatrics, St Mary's Hospital Medical School, London W2 $1 P G$

\section{Spirituality and nursing practice}

Judy Harrison and Philip Burnard, Aldershot, Avebury, 1993, 213 pages, $£ 32$

Spirituality, qualitative research and experiential education are in vogue among nursing opinion-formers. This book concerns all three and is a key approach to contemporary nursing thinking, influenced by North American ideas, particularly 1960s humanistic psychology. The authors are a nurse tutor and a senior nursing lecturer, who is also a prolific writer on psychiatric nursing, spirituality, ethics, experiential education, AIDS, self-awareness, counselling and computers.

The book is written in three sections. The first section surveys current nursing literature on spirituality, overwhelmingly North American, and also includes references to Sartre and Tillich. This section provides the presuppositions for the rest of the book. The position taken, in line with much current nursing thinking on this issue, is that spirituality concerns the existential Angst, the search for personal meaning: although this may be expressed through organized religion, this is merely one mode, which has no basis in any intrinsic metaphysical reality because there is no universal truth. The authors conclude that nurses practising holistic care will need to attend to their patients' existential state and hence will need to explore their own. The second section describes a qualitative study: ten nurses are interviewed and their various opinions on spirituality are interpreted by the authors according to their presuppositions. The final section discusses the experiential education process of facilitating the development of spirituality among nurses through shared group activities. In conclusion the authors discuss their feelings about the study and reiterate their original position.

Four interdependent ethical questions arise. The first concerns the issue of veracity. Does the authors' experiential position, which they claim is representative in nursing, turn significant intellectual questions into descriptions of feelings and hence stifle academic debate? There is no place here for an in-depth, rational and critical analysis of ideas because knowledge is not concerned with the discovery of truth but the uncovering of personal meaning. Thus we are offered no discrimination betwe contradictory statements about what spirituality is, and no discussion their underlying assumptions. Ide $\overline{\text { g }}$. are taken piecemeal to support the authors' position, which often seer confused. So, for example (pages 64-66), the ethical positions of Bish Butler and Charles Kingsley a appropriated without reference $\Phi$ their Christian principles and linked, without differentiation, to Sartress concept of the individual 'entirely alone and abandoned'. The authors proceed to mention Kant, Bentham and J S Mill and conclude that the are no rules of certainty for hum behaviour, after which they assert the rule that 'each person has to bie regarded individually' followed by the statement that 'All patients must bo treated alike'. Although claimed to be liberal and democratic, the authorg, unflinching advocacy of their position might make us wonder if the $\overrightarrow{1 r}$ approach is in fact hiddenly dogmatio.

The next question concerns th theological ethic. Does the authom primary emphasis on spirituality inner meaning undermine the religio $\overrightarrow{y j}$ conception of God as transcen\&efs being and thus the place of worshifor the patient? It is arguable that majority of people, including patients and nurses, regard the spiritual dimension as beyond the seff and linked to God. Ironically, ev요 dence from the study supports this argument, yet even so the authos repeatedly call for the relegation of any traditional religious interpretatio Accordingly, the role of the chaplain virtually ignored, despite his or he्fir being recognised by the nurses interviewed as an invaluable member of the health care team.

The third ethical question conceris intrusiveness and queries the authors expectations that, even unasked, nurses ought to process and counset the deepest feelings of vulnerab patients. Despite noting evidence from this and other studies that nurses aff uncomfortable about initiating such h conversations, the authors do no waver in their opinions. They do, how ever, admit that feelings might be stineulated in patients which the nurse hass inadequate expertise (and we mig add time) to deal with. One wondegs how the nurse would cope with the sit uation which could so easily arise given the authors' predilection for Sartre: the patient sees there is no meaning, life absurd and he or she is alone?

The final ethical question is histo cal. Has this approach separated the 